\title{
Supplemental Insurance and Use of Effective Cardiovascular Drugs Among Elderly Medicare Beneficiaries With Coronary Heart Disease
}

\section{Citation}

Federman, Alex D. 2001. “Supplemental Insurance and Use of Effective Cardiovascular Drugs Among Elderly Medicare Beneficiaries With Coronary Heart Disease." JAMA 286 (14) (October 10): 1732. doi:10.1001/jama.286.14.1732. http://dx.doi.org/10.1001/jama.286.14.1732.

\section{Published Version}

doi:10.1001/jama.286.14.1732

\section{Permanent link}

http://nrs.harvard.edu/urn-3:HUL.InstRepos:32692598

\section{Terms of Use}

This article was downloaded from Harvard University's DASH repository, and is made available under the terms and conditions applicable to Other Posted Material, as set forth at http:// nrs.harvard.edu/urn-3:HUL.InstRepos:dash.current.terms-of-use\#LAA

\section{Share Your Story}

The Harvard community has made this article openly available.

Please share how this access benefits you. Submit a story.

\section{Accessibility}




\section{Supplemental Insurance and Use of Effective Cardiovascular Drugs Among Elderly Medicare Beneficiaries With Coronary Heart Disease}

\begin{tabular}{l}
\hline Alex D. Fe \\
\hline Alyce S. A \\
\hline Dennis Ro \\
Stephen B. \\
\hline John Z. Ay \\
\end{tabular} substantial momentum..$^{1,2}$ However, lawmakers have not reached a consensus on a drug plan design. A major source of the disagreement lies in determining the extent of the financial burden to be placed on beneficiaries through cost-sharing. Cost-sharing strongly influences use of health care resources. ${ }^{3}$ Yet, cost-sharing in many proposals, which reflects cost-sharing in current sources of drug coverage,,, 5 is high. For example, one leading proposal would require a $\$ 53$ monthly premium, a $\$ 250$ annual deductible, and a $50 \%$ co-payment until the recipient paid $\$ 3500$ out-of-pocket each year. ${ }^{6}$

Cost-sharing in drug coverage plans for elderly persons in the United States varies broadly. In 1996, approximately 27 million elderly persons received part or full-year drug coverage from 1 or more of 5 primary sources: current or past employers (49\%); Medicaid (18\%); Medicare-sponsored health maintenance organizations ([HMOs], $16 \%)$; Medigap (14\%); and miscella-

\section{See also p 1762.}

Context Cost-sharing in US prescription drug coverage plans for elderly persons varies widely. Evaluation of prescription drug use among elderly persons by type of health insurance could provide useful information for designing a Medicare drug program.

Objective To determine use of effective cardiovascular drugs among elderly persons with coronary heart disease (CHD) by type of health insurance.

Design, Setting, and Patients Cross-sectional evaluation of 1908 communitydwelling adults, aged 66 years or older, with a history of CHD or myocardial infarction from the 1997 Medicare Current Beneficiary Survey, a nationally representative sample of Medicare beneficiaries.

Main Outcome Measures Use of 3-hydroxy-3-methylglutaryl coenzyme A reductase inhibitors (statins), $\beta$-blockers, and nitrates, and out-of-pocket expenditures for prescription drugs, stratified by type of health insurance: Medicare without drug coverage (Medicare only or self-purchased supplemental insurance) or with drug coverage (Medicaid, other public program, Medigap, health maintenance organization, or employer-sponsored plan).

Results Statin use ranged from $4.1 \%$ in Medicare patients with no drug coverage to $27.4 \%$ in patients with employer-sponsored drug coverage $(P<.001)$. Less variation between these 2 types occurred for $\beta$-blockers $(20.7 \%$ vs $36.1 \% ; P=.003)$ and nitrates $(20.4 \%$ vs $38.0 \% ; P=.005)$. In multivariate analyses, statin use remained significantly lower for patients with Medicare only (odds ratio [OR], 0.16; $95 \%$ confidence interval [Cl], 0.05-0.49) and $\beta$-blocker use was lower for Medicaid patients (OR, $0.55 ; 95 \% \mathrm{Cl}, 0.34-0.88)$ vs those with employer-sponsored coverage. Nitrate use occurred less frequently in persons lacking drug coverage (patients with Medicare only, $P=.049$; patients with supplemental insurance without drug coverage, $P=.03$ ). Patients with Medicare only spent a much larger fraction of income on prescription drugs compared with those with employer-sponsored drug coverage ( $7.9 \%$ vs $1.7 \%$; adjusted $P<.001$ ).

Conclusion Elderly Medicare beneficiaries with CHD who lack drug coverage have disproportionately large drug expenditures and lower use rates of statins, a class of relatively expensive drugs that improve survival.

JAMA. 2001;286:1732-1739

www.jama.com

Author Affiliations: Division of General Medicine, Brigham and Women's Hospital (Drs Federman and Ayanian), and the Departments of Health Care Policy (Drs Federman and Ayanian) and Ambulatory Care and Prevention (Drs Adams, Ross-Degnan, and Soumerai), Harvard Medical School, and Harvard Pilgrim Health Care (Drs Adams, Ross-Degnan, and Soumerai), Boston, Mass. Dr Federman is now with the Departments of Medicine and Psychiatry,
Montefiore Medical Center, Bronx, NY

Financial Disclosure: Dr Ayanian has received grant funding from Merck and Aetna US Healthcare for research studies related to cholesterol therapy.

Corresponding Author and Reprints: John Z. Ayanian, MD, MPP, Department of Health Care Policy Harvard Medical School, 180 Longwood Ave, Boston, MA 02115 (e-mail: ayanian@hcp.med.harvard .edu). 
neous public sources, including state pharmaceutical assistance plans and the Department of Veterans Affairs (3\%). ${ }^{1}$ To illustrate the variation in costsharing, drug co-payments under these programs range from very low in Medicaid $^{7}$ and employer-sponsored coverage ( $\$ 0-\$ 10$ co-payment), ${ }^{8}$ low to high for state pharmacy assistance programs $^{9}$ and Medicare HMOs ( $\leq 50 \%$ copayment) ${ }^{10}$ and very high in Medigap drug plans (50\% co-payment). ${ }^{11}$ Premiums and deductibles vary similarly..$^{7-12}$

Because of variation in cost-sharing, an evaluation of prescription drug use by enrollees of the major types of drug plans could provide important information for the optimal design of a Medicare drug program. Prior studies have had limited adjustment for factors that influence medication use ${ }^{13-15}$ or compared few of the available sources of prescription coverage ${ }^{16-19}$ Furthermore, to our knowledge, only 1 study has focused specifically on medications that prolong survival for patients with a chronic disease (hypertension). ${ }^{16}$

Using coronary heart disease (CHD) as a paradigm of chronic illness, we examined the association between 7 major categories of supplemental prescription drug insurance for elderly Medicare beneficiaries and use of medications that reduce morbidity and mortality. Coronary heart disease is annually responsible for approximately 390000 deaths, 1.2 million hospital discharges ${ }^{20}$ and more than $\$ 26$ billion in health care expenditures in the United States. ${ }^{21}$

Several medications that improve CHD outcomes are often underused, including $\beta$-adrenergic receptor blockers ( $\beta$-blockers) and 3-hydroxy-3methylglutaryl coenzyme A reductase inhibitors (statins). ${ }^{22-24}$ These drugs substantially reduce mortality ${ }^{25-28}$ and are cost-effective. ${ }^{29-33}$ The cost of these medications varies widely. Generic $\beta$-blockers and nitrates cost as little as $\$ 0.11$ per starting dose in 1997 . In contrast, without generic alternatives, statins cost a minimum of $\$ 1.25$ per dose. ${ }^{34}$

We hypothesized that fewer patients without supplemental insur- ance would use statins because of high cost compared with patients having supplemental insurance. We did not anticipate a similar finding for the generally lower cost $\beta$-blockers and nitrates. We also assessed the financial burden of drug expenditures for patients in different insurance plans.

\section{METHODS}

\section{Data Source and Study Population}

We used cross-sectional data from the 1997 Medicare Current Beneficiary Survey (MCBS), ${ }^{35}$ a nationally representative survey of randomly sampled Medicare beneficiaries conducted by the federal Centers for Medicare and Medicaid Services (formerly, the Health Care Financing Administration). Communitydwelling adults participated in a baseline interview and 9 follow-up interviews over 3 years. During follow-up, interviewers collected information on health care services and prescription drug use that occurred since the previous interview. Patients provided medication containers to interviewers to supplement self-reports of specific medication use. Third-party drug payments were determined through self-reports, benefits statements, pharmacy receipts, and Medicaid data (when applicable).

We included patients who reported a history of myocardial infarction (MI) or CHD at baseline, by responding affirmatively to at least 1 of the following questions: "Has a doctor ever told you that you had a myocardial infarction or heart attack?" and "Has a doctor ever told you that you had angina pectoris or coronary heart disease?" We excluded patients who were younger than 66 years, institutionalized, living in Puerto Rico, those with end-stage renal disease, or those with fewer than 12 months of Medicare Part B coverage (FIGURE 1). We also excluded individuals who enrolled too late in the MCBS to participate in the baseline and all follow-up interviews in 1997.

\section{Outcomes and Variables}

We determined the percentage of patients reporting any use of a $\beta$-blocker, statin, or nitrate (intermediate or long-
Figure 1. Eligibility Criteria and Sample Size

12511 Subjects in 1997 Medicare Current Beneficiary Survey

2632 Self-reported History of Myocardial Infarction or Coronary Heart Disease

2320 Age $\geq 66$ y

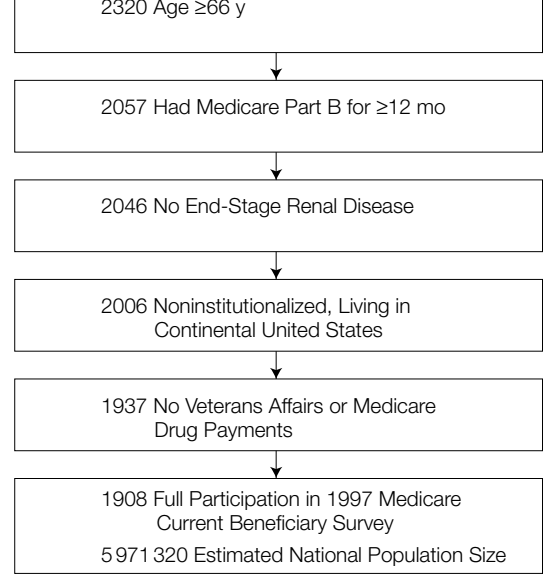

acting) in 1997. We also examined total and out-of-pocket drug expenditures. As a measure of financial burden, we determined the percentage of household income spent out-of-pocket on all prescription drugs. In some cases, outof-pocket expenditures exceeded selfreported income, indicating assistance from family members or other sources to help pay the cost of medications. ${ }^{36}$ If the ratio of out-of-pocket expenditures to income exceeded 1 , the value was set at 1 .

Our analysis focused on 7 insurance categories. The first 2 had no drug coverage and were traditional Medicare fee-for-service only (Medicare only) and self-purchased supplemental insurance (Medigap without drug coverage). Patients were included in the latter group if they had 1 or more months of nonprescription supplemental coverage in 1997 (97\% were covered for 12 months).

Because patients may have had more than 1 source of drug coverage, we designated insurance status according to the supplemental insurance source paying the majority of each beneficiary's drug costs. The 5 categories of drug coverage included Medicaid, other public pro- 
grams (eg, state-sponsored pharmacy assistance programs), self-purchased plans (Medigap with drug coverage), HMO plans, and employer-sponsored plans. We used a single indicator for $\mathrm{HMO}$ coverage because subjects enrolled in Medicare and non-Medicare HMO plans had similar demographic and health status characteristics and rates of cardiovascular drug use. Patients with Veterans Affairs or Medicare drug coverage were excluded because of small sample size (69).

In our analysis of drug use, we adjusted for patient characteristics that might contribute to use of cardiovascular medications or access to prescription drug coverage. ${ }^{16,17,37-39}$ Demographic variables included age, sex, race, income, education, number of household members, urban residence, and Census region. Since qualification for subsidized coverage under many proposed Medicare drug benefits is based on income as a percentage of the federal poverty level $(<135 \%, 135 \%$ $150 \%, 151 \%-200 \%,>200 \%),{ }^{4}$ we used income as a categorical variable in accordance with these percentages (adjusted for 1997 federal poverty levels).

For health status, we included selfreports of current smoking, general health (poor, fair, good, very good, excellent), and the number of limitations in instrumental activities of daily living (ADLs) telephone use, meal preparation, shopping, money management, housework) and basic ADLs (bathing, dressing, eating, rising from chairs, walking, using the toilet). Among comorbid conditions, we included hypertension, diabetes mellitus, stroke, and lung disease (emphysema, asthma, or chronic obstructive pulmonary disease). Finally, we included MI as a covariate because therapy for post-MI patients may differ from that of CHD patients without a history of MI.

\section{Statistical Analysis}

To account for the complex sampling design of the MCBS and to provide nationally representative population estimates, all analyses used patientspecific sampling weights and were performed using SUDAAN statistical software. ${ }^{40}$ We used $\chi^{2}$ tests and 1-way analysis of variance to examine differences in patient characteristics, drug use, and drug-related expenditures between different prescription drug coverage groups. We also calculated 95\% confidence intervals (CIs) for unadjusted rates of drug use and expenditures. For all expenditure analyses, we included only those patients having drug expenditures greater than zero $(96.9 \%)$ and $\log$ transformed the data to approximate the normal distribution.

We determined the odds ratios (ORs) and $95 \%$ CIs for drug use among patients in 6 insurance categories compared with patients with employersponsored drug coverage using weighted multivariable logistic regression. We selected employer-sponsored insurance as the reference category because it generally provides comprehensive and generous coverage ${ }^{8}$ and therefore may best enable access to needed medications. All analyses were adjusted a priori for age, sex, race, income, education, and history of MI. For parsimony, the remaining covariates were included in the models if they had $P<.25$ on univariate analysis. ${ }^{41}$ Covariates were similarly used in weighted ordinary least squares regression to obtain adjusted $P$ values for expenditure data.

Because low-income beneficiaries face relatively large financial obstacles to the purchase of prescription drugs while also experiencing relatively poor health, ${ }^{18}$ we conducted 2 sets of secondary analyses of medication use in this group. First, we compared drug use between insurance categories for patients with household incomes below $150 \%$ of the 1997 federal poverty level, a common criterion for subsidized drug coverage under proposed Medicare drug plans. ${ }^{4,5}$ Second, we examined publicly insured patients, comparing Medicaid enrollees and patients with non-Medicaid public drug coverage or Medicare only. The socioeconomic and health characteristics of individuals in these groups share greater similarity than the characteristics of the publicly and privately insured patients com- bined. ${ }^{16}$ An analysis limited to publicly insured patients may minimize unobserved differences between the groups, thereby having less bias than an analysis comparing privately and publicly insured patients.

\section{RESULTS}

The 1997 MCBS had 12511 subjects; 2632 reported a history of CHD (21\%). After applying exclusion criteria, the final sample included 1908 subjects with CHD (15.3\%) (Figure 1). Sixty patients (3.1\%) reported no medication use and the group with Medicare only had the largest percentage of patients not taking medication (12.9\%). TABLE 1 displays the demographic and clinical characteristics of patients in each insurance group. The mean age in the overall cohort was 76 years. Greater numbers of individuals with public drug coverage other than Medicaid were found in the Northeast (47.3\%) vs the West (17.3\%), South (22.3\%), and Midwest (13.2\%). This observation is consistent with the high concentration of states in the Northeast offering pharmaceutical assistance for elderly persons.

Patients with any form of public insurance had lower incomes and more often reported poor or fair health, deficiencies in instrumental ADLs and basic ADLs and tobacco use vs those with private supplemental insurance. Differences in income and self-reported health status were noted across all groups. The prevalence of hypertension, diabetes, and lung disease also varied (Table 1). However, there were no statistically significant differences in the prevalence of MI or stroke.

\section{Drug Expenditures}

Mean total and out-of-pocket drug expenditures varied markedly among the 7 insurance groups (TABLE 2). Patients with prescription drug coverage had greater total drug expenditures than those without coverage, yet their out-of-pocket expenditures were generally lower. Medigap patients with drug coverage, however, had both high total and out-of-pocket drug expenditures. 
Patients without drug coverage faced the greatest financial burden associated with prescription drug use, spending the largest fractions of income outof-pocket on all prescription drugs (Medicare only, 7.9\%; Medigap without drug coverage, 6.3\%) (Table 2). These values were roughly 4 times the magnitude of burden faced by patients with employer-sponsored plans (1.7\%) and were also substantially higher than that of the other groups with drug coverage $(P<.001$ across all groups).

\section{Prescription Drug Use}

Similar to expenditures, use of cardiovascular drugs varied widely across insurance groups (FIGURE 2). The largest differential occurred for statins, ranging from $4.1 \%$ for patients with Medicare only to $27.4 \%$ for those with employer-sponsored coverage $(P<.001$ across all groups). A narrower range occurred for $\beta$-blockers (20.7\% to $36.1 \%$; $P=.003$ across all groups) and nitrates (20.4\% to $38.0 \% ; P=.005$ across all groups).

The univariate analyses of drug use separately compared the employersponsored group with the other 6 insurance categories (Figure 2). Statin use in most groups was lower than in the

Table 1. Weighted Demographic and Clinical Characteristics of Medicare Beneficiaries With Coronary Heart Disease by Supplemental Insurance Category*

\begin{tabular}{|c|c|c|c|c|c|c|c|c|}
\hline & \multicolumn{2}{|c|}{ Without Drug Coverage } & \multicolumn{5}{|c|}{ With Drug Coverage } & \multirow[b]{2}{*}{$P$ Value $†$} \\
\hline & $\begin{array}{l}\text { Medicare Only } \\
\quad(n=108)\end{array}$ & $\begin{array}{l}\text { Medigap } \\
(\mathrm{n}=434)\end{array}$ & $\begin{array}{l}\text { Medicaid } \\
(\mathrm{n}=194)\end{array}$ & $\begin{array}{l}\text { Other Public } \\
\quad(n=135)\end{array}$ & $\begin{array}{l}\text { Medigap } \\
(n=170)\end{array}$ & $\begin{array}{c}\text { HMO } \\
(n=358)\end{array}$ & $\begin{array}{l}\text { Employer-Sponsored } \\
\qquad(\mathrm{n}=509)\end{array}$ & \\
\hline Population estimate & 307782 & 1319394 & 537309 & 435390 & 536079 & 1143921 & 1691445 & \\
\hline Mean (SD) age, y & $76.5(8.3)$ & $77.4(6.1)$ & $75.8(6.5)$ & $76.2(6.7)$ & $77.4(6.8)$ & $76.2(5.7)$ & $76.3(5.9)$ & .02 \\
\hline Women & 52.3 & 51.9 & 71.1 & 62.1 & 49.7 & 48.5 & 44.1 & $<.001$ \\
\hline White & 77.9 & 94.0 & 56.2 & 83.2 & 97.3 & 83.4 & 94.8 & $<.001$ \\
\hline Education $<12$ y & 85.4 & 73.2 & 93.2 & 75.4 & 68.2 & 72.3 & 64.0 & $<.001$ \\
\hline Married & 39.3 & 58.0 & 27.5 & 46.9 & 58.5 & 55.3 & 67.8 & $<.001$ \\
\hline$\geq 2$ Household members & 65.4 & 71.1 & 53.3 & 65.9 & 70.2 & 69.8 & 73.9 & $<.001$ \\
\hline $\begin{array}{l}\text { Household income } \leq 150 \% \\
\text { of poverty }\end{array}$ & 65.7 & 36.2 & 94.1 & 52.7 & 30.3 & 36.4 & 19.3 & $<.001$ \\
\hline Urban residence & 63.2 & 61.3 & 65.8 & 78.8 & 68.9 & 91.6 & 75.4 & $<.001$ \\
\hline Fair-to-poor general health & 44.0 & 34.4 & 55.5 & 38.4 & 33.1 & 30.2 & 31.1 & $<.001$ \\
\hline$\geq 1$ Instrumental ADL limitation & 26.2 & 26.7 & 40.8 & 33.7 & 22.6 & 19.5 & 20.8 & $<.001$ \\
\hline$\geq 1$ Basic ADL limitation & 10.7 & 12.9 & 21.7 & 16.0 & 14.4 & 8.5 & 7.3 & $<.001$ \\
\hline Current smoker & 21.8 & 7.7 & 20.6 & 14.3 & 7.9 & 10.7 & 7.6 & $<.001$ \\
\hline Myocardial infarction & 68.0 & 68.9 & 66.8 & 65.6 & 60.7 & 64.5 & 63.6 & .29 \\
\hline Coronary heart disease & 57.3 & 64.8 & 68.3 & 64.9 & 70.8 & 68.6 & 73.8 & .02 \\
\hline Hypertension & 65.5 & 67.1 & 80.4 & 76.5 & 62.3 & 68.0 & 65.9 & .01 \\
\hline Diabetes & 18.9 & 19.4 & 29.9 & 27.5 & 19.9 & 24.8 & 21.1 & .046 \\
\hline Stroke & 24.0 & 18.9 & 28.1 & 23.0 & 16.8 & 18.7 & 19.0 & .12 \\
\hline Lung disease & 16.4 & 17.8 & 36.5 & 16.1 & 20.4 & 13.3 & 16.4 & $<.001$ \\
\hline
\end{tabular}

*Values are expressed as percentages unless otherwise indicated. $\mathrm{HMO}$ indicates health maintenance organization; ADL, activities of daily living. $\dagger \chi^{2}$ Test for differences across all groups.

Table 2. Weighted Total and Out-of-Pocket Prescription Drug Expenditures and Percentage of Household Income Spent Out-of-Pocket on Prescription Drugs in $1997^{*}$

\begin{tabular}{|c|c|c|c|c|c|c|}
\hline & \multicolumn{4}{|c|}{ Expenditures } & \multirow[b]{2}{*}{$\begin{array}{l}\text { Household Income } \\
\text { Spent Out-of-Pocket, } \\
\text { Mean }(95 \% \mathrm{Cl}), \%\end{array}$} & \multirow[b]{2}{*}{$P$ Value } \\
\hline & $\begin{array}{c}\text { Total, } \\
\text { Mean }(95 \% \mathrm{Cl}), \$ \\
\end{array}$ & $P$ Value† & $\begin{array}{l}\text { Out-of-Pocket, } \\
\text { Mean (95\% Cl), \$ }\end{array}$ & $P$ Value† & & \\
\hline $\begin{array}{l}\text { Without drug coverage } \\
\text { Medicare only }\end{array}$ & $702(107)$ & $<.001$ & $680(105)$ & $<.001$ & $7.9(2.4)$ & $<.001$ \\
\hline Medigap & $952(80)$ & $<.001$ & $919(76)$ & $<.001$ & $6.3(1.0)$ & $<.001$ \\
\hline $\begin{array}{l}\text { With drug coverage } \\
\text { Medicaid }\end{array}$ & $1361(141)$ & .91 & $204(47)$ & .60 & $2.9(0.8)$ & .34 \\
\hline Other public & $1427(259)$ & .88 & $409(67)$ & $<.001$ & $3.7(1.0)$ & $<.001$ \\
\hline Medigap & $1218(167)$ & .78 & $718(92)$ & $<.001$ & $4.4(0.8)$ & $<.001$ \\
\hline Health maintenance organization & $1038(120)$ & $<.001$ & $381(49)$ & .07 & $2.6(0.4)$ & .02 \\
\hline Employer-sponsored & $1271(94)$ & NA $\ddagger$ & 337 (29) & NA & $1.7(0.2)$ & NA $\ddagger$ \\
\hline
\end{tabular}


employer-sponsored group, most strikingly so for patients with Medicare only $(4.1 \%$ vs $27.4 \% ; P<.001)$. Only the other public and Medigap with drug coverage groups had comparable rates. In contrast, just 2 groups had significantly lower $\beta$-blocker use compared with the employer-sponsored patients, Medicare only $(23.6 \%$ vs $33.4 \% ; P=.01)$, and Medicaid (20.7\% vs 33.4\%; $P=.001)$. No group had significantly lower nitrate use than the employer-sponsored group (27.0\%). Rather, individuals with Medicaid and other public drug coverage used nitrates more frequently than employer-sponsored patients $(37.1 \%$ $[P=.01]$ and $38.0 \% \quad[P=.01]$, respectively).

Several comparisons remained significant after accounting for socioeconomic and health factors that might influence treatment of CHD. FIGURE 3 shows the adjusted ORs for use of each drug class. Patients with Medicare only were the only group that was significantly less likely to use statins than patients with employer-sponsored coverage (OR, 0.16; 95\% CI, 0.05-0.49). Significantly lower ORs were evident for nitrate use among patients with Medicare only (OR, $0.63 ; 95 \%$ CI, 0.400.99 ) and patients who had supplemental insurance without drug coverage (OR, 0.71; 95\% CI, 0.51-0.97). For $\beta$-blockers, only Medicaid patients had a lower OR, which was 0.55 (95\% CI, $0.34-0.88$ ). Low income was also a significant independent predictor of reduced drug use for statins and nitrates, but not for $\beta$-blockers, in adjusted analyses (data not shown).

In the multivariate subgroup analysis of beneficiaries with household incomes at or below $150 \%$ of the federal poverty level, coverage with Medicare only was again associated with lower rates of statin use in comparison with employer-sponsored coverage (OR, 0.19; $95 \%$ CI, 0.05-0.78). Nitrate use in this analysis was significantly greater among patients with other public drug coverage relative to employer-sponsored coverage (OR, 2.13, 95\% CI, 1.01-4.48); no other comparison attained statistical significance. $\beta$-Blocker use did not differ significantly for any group (all $P>.05$ ). The multivariate subgroup analysis of publicly insured patients compared Medicaid coverage to Medicare only and non-Medicaid public drug coverage. Once again, patients with Medicare only had markedly lower adjusted rates of statin use (OR, 0.20; 95\% CI, 0.060.68 ) while $\beta$-blocker and nitrate use were not significantly different. No other comparisons were significant.

In a post-hoc analysis, we examined the impact of sex on the association be-

Figure 2. Prescription Drug Use by Elderly Medicare Beneficiaries With Coronary Heart Disease

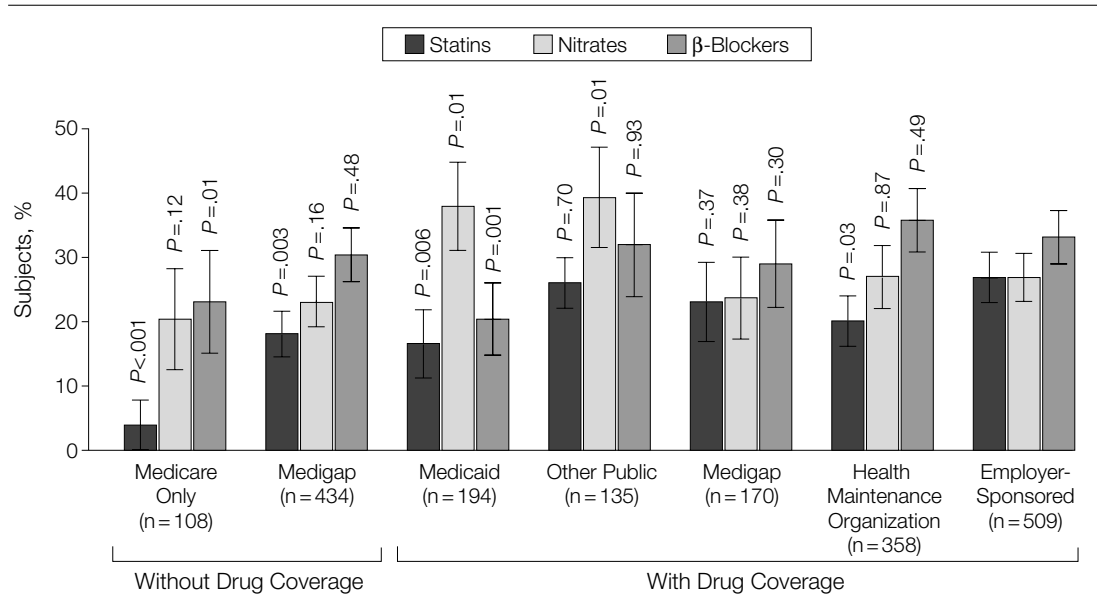

This is a weighted analysis. Error bars represent $95 \%$ confidence intervals. $P$ values are for comparisons with employer-sponsored drug coverage. tween drug use and coverage. We found no material differences in the association of these 2 factors between men and women.

\section{COMMENT}

This study examined the association of supplemental insurance and use of specific types of drugs among elderly patients with CHD. Our findings show that use of effective drugs among elderly Medicare beneficiaries with CHD varies widely with coverage type as well as drug class. Although we could not determine which patients had a specific indication for statin therapy, we found that fewer patients without supplemental drug coverage used statins than those with supplemental coverage. This finding remained significant after adjustment for socioeconomic and health characteristics and may be explained by the higher cost of statins relative to $\beta$-blockers and nitrates. Patients with Medicare only had high outof-pocket drug expenditures and paid the largest fraction of household income on prescription medications. Thus, patients with Medicare only may have chosen to purchase nitrates and $\beta$-blockers over statins, despite the growing importance of statins in CHD management.

Unlike patients with Medicare only, enrollees in Medicaid and other public drug assistance programs face little cost-sharing, as reflected in their relatively low out-of-pocket drug expenditures. These patients used statins and nitrates at rates comparable with patients with employer-sponsored insurance, a generally comprehensive and generous form of drug coverage. ${ }^{8}$ Similarly, patients with Medicare HMO drug coverage in our study had low out-ofpocket drug expenditures, and they also had a higher rate of statin use than patients with Medicare only.

We found that significantly fewer Medicaid patients than patients with employer-sponsored drug coverage had taken $\beta$-blockers. One study has also reported low rates of $\beta$-blocker use among Medicaid and state pharmacy assistance program enrollees. ${ }^{42}$ In addi- 
tion, this prior study observed greater use of calcium-channel blockers than $\beta$-blockers, suggesting that physicians may substitute these medications in Medicaid populations. In our cohort, a large number of Medicaid recipients used calcium-channel blockers as well (44\%), the second highest rate after patients with other public drug coverage (range, $24 \%-45.8 \%)$. The substantial reduction in CHD-related mortality associated with $\beta$-blockers ${ }^{27,28}$ underscores the importance of ensuring their use among all eligible patients while avoiding potentially ineffective or harmful substitutes, such as calcium-channel blockers. ${ }^{43}$

Enrollees of self-purchased supplemental insurance plans (Medigap), with or without drug coverage, had high rates of statin and $\beta$-blocker use. However, individuals in both groups paid significantly more of their household income out-of-pocket for prescription medications, consistent with drug expenditures by elderly patients with hypertension in these groups. ${ }^{16,17}$ Large out-of-pocket expenditures by Medigap beneficiaries result, in part, from heavy cost-sharing. Standard Medigap plans with drug coverage require a $\$ 250$ deductible and a 50\% co-payment on prescriptions, and they cover only $\$ 1250$ to $\$ 3000$ in drug expenses per year. ${ }^{11}$ In addition, Medigap premiums are expensive: $\$ 106$ to $\$ 124$ per month for plans without drug coverage, and \$286 to $\$ 314$ for plans with drug coverage in Massachusetts during 2001. ${ }^{12}$ Expensive premiums, heavy cost-sharing, and low reimbursement caps may offset the savings from Medigap reimbursement of drug purchases for many patients. Both groups of patients with Medigap plans in our study may have been able to afford most or all of their medications despite high insurance costs because of their relatively high average incomes.

Lower income Medicare beneficiaries may be unable to afford this expensive coverage. Although proposed Medicare drug plans typically set higher limits on reimbursements, their deductible and copayment structures otherwise resemble those of Medigap drug plans. ${ }^{2,4,5}$ Thus, while most proposed plans would improve access to medications for the majority of individuals without drug coverage, heavy costsharing might sharply restrict this access for many low-income beneficiaries, especially those with multiple chronic diseases. Indeed, use of medications by low-income elderly persons is exquisitely sensitive to even modest variations in cost-sharing, as is use of other health services and health outcomes. ${ }^{19,38,44-48}$

Our study has several notable limitations. Cross-sectional analyses of insurance coverage and use of goods and services are susceptible to bias through adverse selection. ${ }^{18,39,49,50}$ Adverse se-

Figure 3. Adjusted Odds Ratios for Cardiovascular Drug Use by Elderly Medicare Beneficiaries With Coronary Heart Disease
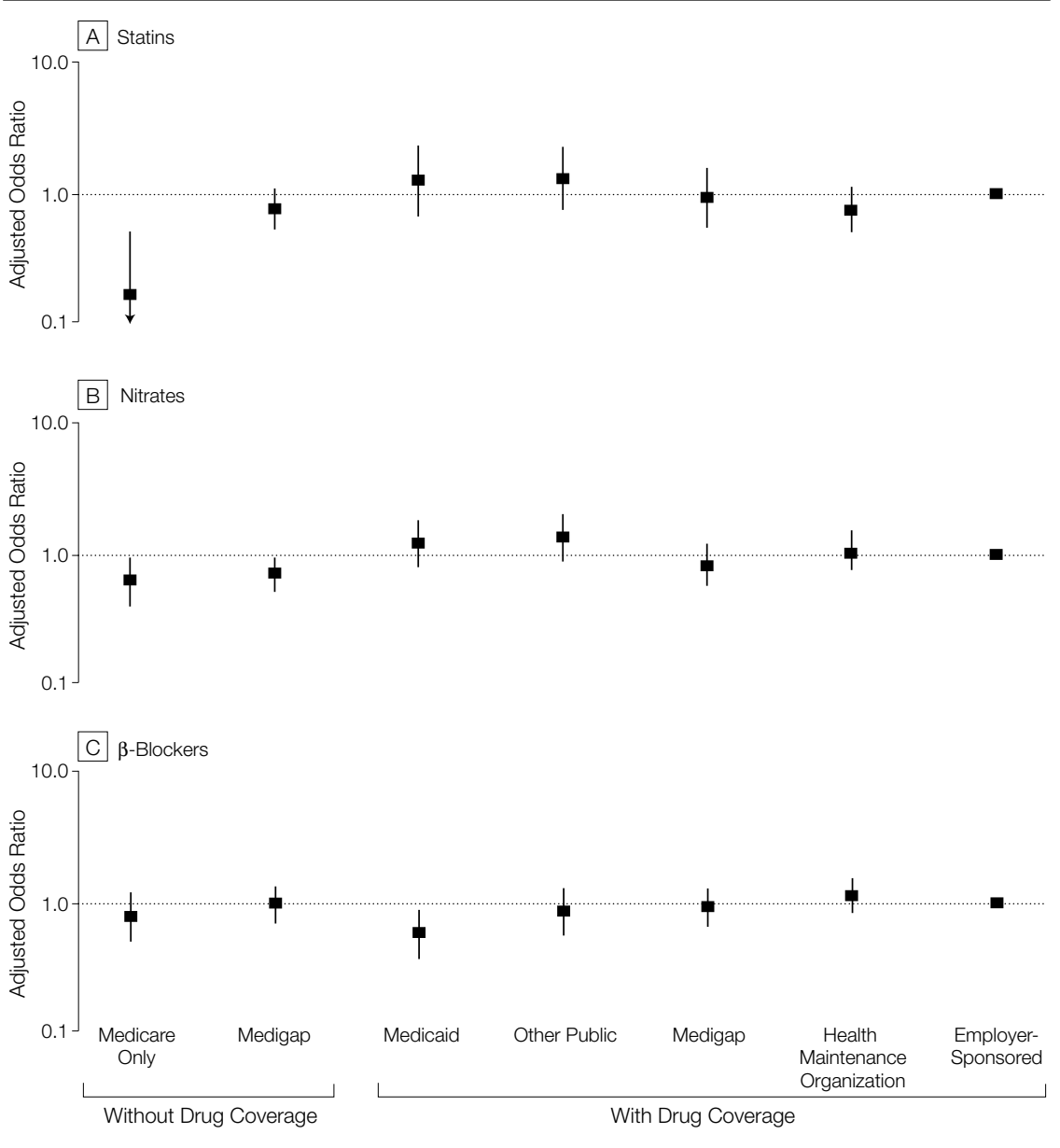

This is a weighted analysis. Employer-sponsored drug coverage is the reference group. Odds ratios are adjusted for demographic and health status variables. Vertical bars represent $95 \%$ confidence intervals. 
drug coverage. ${ }^{18,39,51}$ Furthermore, in subgroup analyses of low-income and publicly insured patients, patients with Medicare only in our study had lower statin use vs patients with employersponsored or Medicaid drug coverage, respectively.

We did not have any information regarding drug prescriptions that patients received but did not fill or whether they had stopped taking medications due to adverse effects or cost. We also had no measures of hyperlipidemia. Consequently, we cannot distinguish whether low statin use among patients with Medicare only resulted from an inability to pay for the drugs or a lack of indication. Nonetheless, 2 observations suggest that the low percentage of these patients using statins reflects relative undertreatment. First, they had similar or worse health than those with drug coverage, suggesting a similar need for lipidlowering therapy. Second, use of cholesterol-lowering medications in other studies ranged from $29 \%$ to $47 \%$ among patients with CHD during this period, ${ }^{23,52-54}$ and other studies suggest that approximately $60 \%$ of patients with CHD are appropriate candidates for statin therapy. ${ }^{24,55,56}$ However, in our study only $5.8 \%$ of patients with Medicare only took any type of lipid-lowering agent, and only $4.1 \%$ took statins even though their efficacy in older adults had been demonstrated before $1997 .^{57,58}$

Lastly, reliance on self-reports could have resulted in underestimation of cardiovascular drug use. ${ }^{59,60}$ However, MCBS interviewers made substantial efforts to accurately record drug use, thereby enhancing the validity of selfreports.

\section{Conclusion}

Despite numerous sources of prescription drug coverage, approximately 10 million elderly persons in the United States do not have such coverage. ${ }^{14}$ Our data indicate that those lacking coverage less frequently take statins, an expensive class of drugs that improve survival in most patients with CHD. This finding may reflect the large financial burden of medication costs faced by pa- tients without coverage. With heavy costsharing and no accommodation for illness burden, a universal drug plan for elderly persons might fail to provide sufficient access to necessary medications for many low-income beneficiaries. Providing adequate coverage for effective medications could reduce adverse events among low-income patients with chronic illnesses and help avoid costly hospitalizations and procedures. ${ }^{47}$ To improve rates of essential drug use for economically vulnerable patients, a Medicare drug plan may require consideration of health status to target subsidy recipients and offer more generously subsidized coverage than would be provided in current proposals. Policymakers could also focus greater attention on enrolling qualified elderly patients in Medicaid and promoting the development of state pharmacy assistance programs. ${ }^{1,2}$ Without such interventions, the most vulnerable may fail to receive effective drugs for major chronic illnesses.

Author Contributions: Study concept and design: Federman, Adams, Ross-Degnan, Soumerai, Ayanian. Acquisition of data: Federman, Ayanian. Analysis and interpretation of data: Federman, Adams, Ross-Degnan, Soumerai, Ayanian.

Drafting of the manuscript: Federman.

Critical revision of the manuscript for important intellectual content: Federman, Adams, Ross-Degnan, Soumerai, Ayanian.

Statistical expertise: Federman, Adams, RossDegnan, Soumerai, Ayanian.

Obtained funding: Ayanian.

Administrative, technical, or material support: Federman, Ross-Degnan, Soumerai.

Study supervision: Ross-Degnan, Soumerai, Ayanian. Funding/Support: This study was supported in part by Institutional National Research Service Award 5T32PE11001-13 from the Health Resources and Services Administration (Dr Federman) and by the Primary Care Research Fund of Brigham and Women's Hospital.

Acknowledgment: We are grateful to Robert Wolf, MS, and Matthew Cioffi for programming assistance and Mary Beth Landrum, PhD, for advice regarding statistical analyses.

\section{REFERENCES}

1. Stuart B, Briesacher B. Designing a Medicare Drug Benefit: Whose Needs Will Be Met? New York, NY: Commonwealth Fund; 2000. Available at: http://www.cmwf.org/programs/medfutur /stuart_designing_pb_436.pdf. Accessibility verified September 5, 2001

2. Soumerai $S B$, Ross-Degnan D. Inadequate prescription-drug coverage for Medicare enrollees-a call to action. N Eng/ J Med. 1999;340:722-728.

3. Adams AS, Soumerai SB, Ross-Degnan D. The case for a Medicare drug coverage benefit: a critical review of the empirical evidence. Annu Rev Public Health. 2001;22:49-61.

4. Prescription drug coverage for Medicare benefi- ciaries: a side-by-side comparison of selected proposals. In: Health Policy Alternatives I. Washington, DC Henry J. Kaiser Family Foundation; 2000

5. McClellan M, Spatz ID, Carney S. Designing a Medicare prescription drug benefit: issues, obstacles, and opportunities. Health Aff (Millwood). 2000;19:26-41.

6. Pear R, Toner R. Despite high hopes, drug plan may be disappointing to elderly. New York Times. July 22, 2001; sect A:1.

7. Stuart B, Zacker C. Who bears the burden of Medicaid drug copayment policies? Health Aff (Millwood). 1999:18:201-212.

8. Jensen GA, Morrisey MA. Employer-sponsored postretirement health benefits: not your mother's Medigap plan. Gerontologist. 1992;32:693-703.

9. Gross D. State Pharmacy Assistance Programs. Washington, DC: AARP Public Policy Institute; 1999 10. Cassidy A, Gold M. Medicare + Choice in 2000: Will Enrollees Spend More and Receive Less? New York, NY: Commonwealth Fund; 2000. Available at: http://www.cmwf.org/programs/medfutur /cassidy_choice_394.pdf. Accessibility verified September 5, 2001

11. AARP Web site. Educated health care choices: selecting Medicare supplemental insurance. Medigap coverage by benefit. Available at: http://www.aarp .org/hcchoices/medicare/supplement/coverageb html. Accessibility verified September 11, 2001.

12. Massachusetts State Web site. Massachusetts Division of Insurance, Consumer Service. Three standard Medigap plans offered in Massachusetts: comparison of plan types. Available at: http://www.state ma.us/doi/Consumer/css_health_medsupproducts html. Accessibility verified September 11, 2001.

13. Poisal JA, Chulis GS. Medicare beneficiaries and drug coverage. Health Aff (Millwood). 2000;19:248256.

14. Poisal JA, Murray L. Growing differences between Medicare beneficiaries with and without drug coverage. Health Aff (Millwood). 2001;20:74-85. 15. Davis M, Poisal J, Chulis G, Zarabozo C, Cooper B. Prescription drug coverage, utilization, and spending among Medicare beneficiaries. Health Aff (Millwood). 1999;18:231-243.

16. Adams AS, Soumerai SB, Ross-Degnan D. Use of antihypertensive drugs by Medicare enrollees: does type of drug coverage matter? Health Aff (Millwood). 2001;20:276-286.

17. Blustein J. Drug coverage and drug purchases by Medicare beneficiaries with hypertension. Health Aff (Millwood). 2000;19:219-230.

18. Long SH. Prescription drugs and the elderly: issues and options. Health Aff (Millwood). 1994;13: 157-174.

19. Stuart B, Grana J. Ability to pay and the decision to medicate. Med Care. 1998;36:202-211.

20. American Heart Association Web site. 2001 Heart and stroke statistical update: coronary heart disease. Available at: http://americanheart.org/statistics /coronary.html. Accessibility verified September 5, 2001.

21. Hodgson TA, Cohen AJ. Medical care expenditures for selected circulatory diseases: opportunities for reducing national health expenditures. Med Care. 1999;37:994-1012.

22. Wang TJ, Stafford RS. National patterns and predictors of $\beta$-blocker use in patients with coronary artery disease. Arch Intern Med. 1998;158:19011906.

23. Majumdar SR, Gurwitz JH, Soumerai SB. Undertreatment of hyperlipidemia in the secondary prevention of coronary artery disease. J Gen Intern Med. 1999; 14:711-717.

24. Seddon M, Ayanian JZ, Landrum MB, et al. Quality of ambulatory care after myocardial infarction among Medicare patients by type of insurance and region. Am J Med 2001:111:24-32.

25. Long-Term Intervention with Pravastatin in Is- 
chaemic Disease (LIPID) Study Group. Prevention of cardiovascular events and death with pravastatin in patients with coronary heart disease and a broad range of initial cholesterol levels. N Engl J Med. 1998;339: 1349-1357.

26. Pedersen $T R$, Wilhelmsen $L$, Faergeman $O$, et al. Follow-up study of patients randomized in the Scandinavian simvastatin survival study (4S) of cholesterol lowering. Am J Cardiol. 2000;86:257-262.

27. Hjalmarson A. International $\beta$-blocker review in acute and postmyocardial infarction. Am J Cardiol. 1988;61:26B-29B.

28. Viscoli $C M$, Horwitz RI, Singer $B H$. $\beta$-blockers after myocardial infarction: influence of first-year clinical course on long-term effectiveness. Ann Intern Med. 1993:118:99-105.

29. Bowlin SJ, Morrill BD, Nafziger AN, Jenkins PL, Lewis C, Pearson TA. Validity of cardiovascular disease risk factors assessed by telephone survey: the Behavioral Risk Factor Survey. J Clin Epidemiol. 1993; 46:561-571.

30. Ganz DA, Kuntz KM, Jacobson GA, Avorn J. Costeffectiveness of 3-hydroxy-3-methylglutaryl coenzyme $A$ reductase inhibitor therapy in older patients with myocardial infarction. Ann Intern Med. 2000; 132:780-787

31. Goldman L, Sia ST, Cook EF, Rutherford JD, Weinstein MC. Costs and effectiveness of routine therapy with long-term beta-adrenergic antagonists after acute myocardial infarction. N Engl J Med. 1988;319:152157.

32. Phillips KA, Shlipak MG, Coxson P, et al. Health and economic benefits of increased $\beta$-blocker use following myocardial infarction. JAMA. 2000;284:27482754.

33. Prosser LA, Stinnett AA, Goldman PA, et al. Costeffectiveness of cholesterol-lowering therapies according to selected patient characteristics. Ann Intern Med. 2000;132:769-779.

34. Drug Topics Red Book. 101st ed. Montvale, NJ: Medical Economics Co Inc; 1997.

35. Adler GS. A profile of the Medicare Current Beneficiary Survey. Health Care Financ Rev. 1994;15: 153-163.

36. Alecxih L, Corea J, Gross D, Caplan C, Brangan $\mathrm{N}$, Gibson MJ. In reply to: Methodological biases in estimating the burden of out-of-pocket expenses. Health Serv Res. 2001;35:1365-1370.

37. Rice T, McCall N, Boismier JM. The effectiveness of consumer choice in the Medicare supplemental health insurance market. Health Serv Res. 1991;26: 223-246.

38. Avorn J, Monette J, Lacour A, et al. Persistence of use of lipid-lowering medications: a cross-national study. JAMA. 1998;279:1458-1462.

39. Ettner SL. Adverse selection and the purchase of Medigap insurance by the elderly. J Health Econ. 1997; 16:543-562.

40. Research Triangle Institute. Professional Software for Survey Data Analysis (SUDAAN) User's Manual, Release 7.5. Research Triangle Park, NC: Research Triangle Institute; 1997.

41. Hosmer DL. Applied Logistic Regression. New York, NY: John Wiley \& Sons Inc; 1989:82-134.

42. Soumerai SB, McLaughlin TJ, Spiegelman D, Hertzmark E, Thibault G, Goldman L. Adverse outcomes of underuse of $\beta$-blockers in elderly survivors of acute myocardial infarction. JAMA 1997:277: 115-121.

43. Furberg CD, Psaty BM, Meyer JV. Nifedipine: dose-related increase in mortality in patients with coronary heart disease. Circulation. 1995;92:13261331

44. Johnson RE, Goodman MJ, Hornbrook MC, Eldredge $M B$. The impact of increasing patient prescription drug cost sharing on therapeutic classes of drugs received and on the health status of elderly $\mathrm{HMO}$ members. Health Serv Res. 1997;32:103-122.

45. Soumerai SB, Avorn J, Ross-Degnan D, Gortmaker $\mathrm{S}$. Payment restrictions for prescription drugs under Medicaid: effects on therapy, cost, and equity. N Engl J Med. 1987;317:550-556.

46. Soumerai SB, Ross-Degnan D, Avorn J, McLaughlin T, Choodnovskiy I. Effects of Medicaid drugpayment limits on admission to hospitals and nursing homes. N Engl I Med. 1991:325:1072-1077.

47. Soumerai SB, McLaughlin TJ, Ross-Degnan D, Casteris CS, Bollini P. Effects of a limit on Medicaid drugreimbursement benefits on the use of psychotropic agents and acute mental health services by patients with schizophrenia. N Engl J Med. 1994;331:650655.

48. Tamblyn R, Laprise R, Hanley JA, et al. Adverse events associated with prescription drug costsharing among poor and elderly persons. JAMA. 2001; 285:421-429.

49. Davidson BN, Sofaer S, Gertler P. Consumer information and biased selection in the demand for cov- erage supplementing Medicare. Soc Sci Med. 1992; 34:1023-1034.

50. Wolfe JR, Goddeeris JH. Adverse selection, moral hazard, and wealth effects in the Medigap insurance market. J Health Econ. 1991;10:433-459.

51. Vistnes JP, Banthin JS. The demand for Medicare supplemental insurance benefits: the role of attitudes toward medical care and risk. Inquiry. 1997;34 311-324.

52. Harnick DJ, Cohen JL, Schechter CB, Fuster V, Smith DA. Effects of practice setting on quality of lipidlowering management in patients with coronary artery disease. Am J Cardiol. 1998;81:1416-1420.

53. Miller $M$, Byington $R$, Hunninghake $D$, Pitt $B$, Furberg $C D$, for the Prospective Randomized Evaluation of the Vascular Effects of Norvasc Trial (PREVENT) Investigators. Sex bias and underutilization of lipidlowering therapy in patients with coronary artery disease at academic medical centers in the United States and Canada. Arch Intern Med. 2000;160:343-347. 54. Schrott HG, Bittner V, Vittinghoff E, Herrington DM, Hulley S, for the HERS Research Group. Adherence to National Cholesterol Education Program: treatment goals in postmenopausal women with heart disease: the Heart and Estrogen/Progestin Replacement Study (HERS). JAMA. 1997;277:1281-1286.

55. Sempos CT, Cleeman JI, Carroll MD, et al. Prevalence of high blood cholesterol among US adults: an update based on guidelines from the second report of the National Cholesterol Education Program Adult Treatment Panel. JAMA. 1993;269:3009-3014

56. Jackevicius CA, Tu JV, Leiter L, Anderson GM. Impact of the results of the landmark 4S Lipid Lowering Trial on prescribing habits for an elderly population. J Am Coll Cardiol. 2000;35(suppl 1):314A

57. Randomised trial of cholesterol lowering in 4444 patients with coronary heart disease: the Scandinavian Simvastatin Survival Study (4S). Lancet. 1994; 344:1383-1389.

58. Sacks FM, Pfeffer MA, Moye LA, et al. The effect of pravastatin on coronary events after myocardial infarction in patients with average cholesterol levels. N Engl J Med. 1996;335:1001-1009.

59. Berk ML, Schur CL, Mohr P. Using survey data to estimate prescription drug costs. Health Aff (Millwood). 1990;9:146-156.

60. Moeller JF, Mathiowetz NA. Correcting errors in prescription drug reporting: a critique. Health Aff (Millwood). 1991;10:210-214. 